九州大学学術情報リポジトリ

Kyushu University Institutional Repository

\title{
Numerical Study on Saltwater Instrusion in a Heterogeneous Stratified Aquifer
}

Nakagawa, Ke i

Laboratory of Soil Science, Division of Soil Science and Plant Production, Department of Plant

Resources, Faculty of Agriculture, Graduate School, Kyushu University

Jinno, Kenji

Faculty of Engineering, Kyushu University

Hosokawa, Tosao

Faculty of Engineering, Kyushu Sangyo University

Iwam i tsu, Kouse i

Faculty of Engineering, Kyushu Sangyo University

https://doi.org/10.5109/24381

出版情報: 九州大学大学院農学研究院紀要. 45 (1)，pp.317-323，2000-11. Kyushu University バージョン：

権利関係 : 


\title{
Numerical Study on Saltwater Intrusion in a Heterogeneous Stratified Aquifer
}

\author{
Kei NAKAGAWA, Kenji JINNO*, Tosao HOSOKAWA** \\ and Kousei IWAMITSU**
}

\author{
Laboratory of Soil Science, Division of Soil Science and Plant Production, Department of \\ Plant Resources, Faculty of Agriculture, Graduate School, \\ Kyushu University, Fukuoka 812-8581, Japan \\ (Received June 12, 2000 and accepted August 18, 2000)
}

\begin{abstract}
In a costal aquifer, saltwater intrusion is frequently observed due to an excess exploitation. There are many researches focused on the saltwater intrusion. However, there are few researches, which take into consideration the mixing processes in a stratified heterogeneous aquifer. In the present study, a laboratory experiment and numerical simulation are made in order to understand the phenomena in a stratified heterogeneous aquifer. The result of the numerical analysis agrees well with the measurement and indicates that the saltwater intrusion with the mixing process is dominated by the convection in the high permeable layer and the molecular diffusion in the low permeable layer.
\end{abstract}

\section{INTRODUCTION}

In spite of high precipitation in the islands or peninsula areas in the Okinawa Archipelagos, water shortage frequently takes place due to the luck in the geological conditions for the construction of surface dams. Therefore, several projects of subsurface dam are planned and already constructed in order to meet the water demand. For planning subsurface dams, it is necessary to evaluate groundwater flow and the probable problems, which may be caused by the constructions. Saltwater intrusion need to be taken into consideration when a subsurface dam is constructed near coast. If fresh water table is lowered due to exploitation, saltwater intrusion should occur. Various studies and models have been presented (Henry, 1959; Bear and Dagan, 1964; Pinder and Cooper, 1970; among others). Collins and Gelher (1971) and Mualem and Bear (1974) discussed saltwater intrusion in stratified aquifers. However, these studies are based on Dupuit assumption and only few attempts have so far been made for the 2 dimensional analysis on heterogeneous stratified aquifer with declined layers. In the present study, a laboratory experiment and a numerical simulation are made. It is shown that the saltwater intrusion in a stratified aquifer is complicated near the borders of the layer. The field observation for the saltwater intrusion, therefore, should be carefully made taking account for the detailed mixing processes.

\footnotetext{
* Faculty of Engineering, Kyushu University, Fukuoka 812-8581, Japan

** Faculty of Engineering, Kyushu Sangyo University, Fukuoka 813-8503, Japan
} 


\section{BASIC EQUATIONS FOR THE NUMERICAL ANALYSIS}

In the numerical study, the groundwater flow equation (equation 1) and the salt transport equation (equation 2) are applied. The density term is considered in the groundwater flow equation.

$$
\begin{aligned}
& \left(C_{W}+\beta S_{s}\right) \frac{\partial h}{\partial t}=\frac{\partial}{\partial x}\left[k \frac{\partial h}{\partial x}\right]+\frac{\partial}{\partial y}\left[k\left(\frac{\partial h}{\partial y}+\frac{\rho}{\rho_{f}}\right)\right] \\
& \frac{\partial(\theta C)}{\partial t}+\frac{\partial\left(u^{\prime} \theta C\right)}{\partial x}+\frac{\partial\left(v^{\prime} \theta C\right)}{\partial y}=\frac{\partial}{\partial x}\left(\theta D_{x y} \frac{\partial C}{\partial x}+\theta D_{x y} \frac{\partial C}{\partial y}\right)+\frac{\partial}{\partial y}\left(\theta D_{y x} \frac{\partial C}{\partial x}+\theta D_{y y} \frac{\partial C}{\partial y}\right)
\end{aligned}
$$

where, $C_{W}$ is the specific moisture capacity, $S_{s}$ is the specific storage coefficient, $k$ is the hydraulic conductivity ( $\mathrm{L} / \mathrm{T}), h$ is the pressure head $(\mathrm{L}), u$ ' and $v$ ' are the pore velocities for $x$ and $y$ directions $(\mathrm{L} / \mathrm{T}), \rho$ is the density $\left(\mathrm{M} / \mathrm{L}^{3}\right), C\left(=\left(\rho-\rho_{f}\right) /\left(\rho_{s}-\rho_{f}\right) \times 100\right)$ is the normalized salt concentration (\%), $\rho_{f}$ and $\rho_{s}$ are fresh and saltwater densities, $D_{x x}, D_{x y}$, $D_{y y}$ and $D_{y x}$ are the dispersivities $\left(\mathrm{L}^{2} / \mathrm{T}\right)$, and $\beta$ is the dummy parameter $(\beta=0$ : in the unsaturated zone, $\beta=1$ : in the saturated zone).

The dispersivities are defined as follows (Huyakorn and Pinder, 1983);

$$
\begin{aligned}
& D_{x x}=\frac{\alpha_{L} u^{\prime 2}}{V}+\frac{\alpha_{T} v^{\prime 2}}{V}+D_{M} \\
& D_{y y}=\frac{\alpha_{T} u^{\prime 2}}{V}+\frac{\alpha_{L} v^{\prime 2}}{V}+D_{M} \\
& D_{x y}=D_{y x}=\frac{\left(\alpha_{L}-\alpha_{T}\right) u^{\prime} v^{\prime}}{V}
\end{aligned}
$$

where, $V=\left(u^{\prime 2}+v^{\prime 2}\right)^{1 / 2}, \alpha_{\mathrm{L}}$ is the longitudinal dispersivity $(\mathrm{L}), \alpha_{\mathrm{T}}$ is the transverse dispersivity (L), and $D_{M}$ is the molecular diffusion coefficient $\left(\mathrm{L}^{2} / \mathrm{T}\right)$.

\section{EXPERIMENTAL STUDY}

Figure 1 shows the experimental apparatus. The apparatus consists of a $60 \mathrm{~cm}$ length $\times 60 \mathrm{~cm}$ height $\times 15 \mathrm{~cm}$ width seepage layer with two water tanks. Upper and lower boundaries are sectioned with wire screens. The seepage flow is controlled by the head difference between the upper and lower tanks. The heterogeneous seepage layers are made of 5 kinds of soils as shown in Fig. 1. The hydraulic conductivity and soil diameter of each layer are given in Table 1. The experiment is conducted as follows; the head difference between upper and lower tanks is maintained $6.0 \mathrm{~cm}$. Under this condition, saltwater dose not intrude into the seepage layer. Then, the head difference is changed to $0.75 \mathrm{~cm}$. The saltwater starts to intrude into the seepage layer.

\section{RESULTS AND DISCUSSION}

A combined implicit finite difference and Gauss-Seidel method is employed for the groundwater flow equation. The method of characteristics (MOC) is used for the salt transport equation (Pinder and Cooper, 1970; Jinno and Ueda, 1978). The simulation 


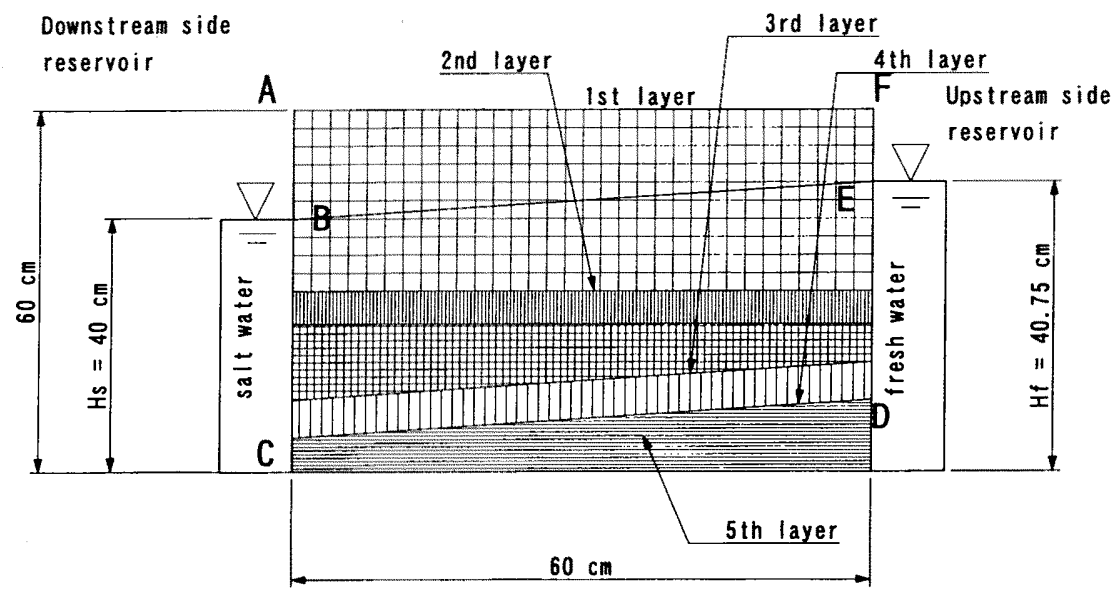

Fig. 1. Experimental apparatus

Table 1. Diameters and hydraulic conductivities

\begin{tabular}{ccc}
\hline layer & soil diameter $(\mathrm{mm})$ & hydraulic conductivity $(\mathrm{cm} / \mathrm{s})$ \\
\hline $1 \mathrm{st}$ & $0.250-2.000$ & $3.23 \times 10^{-1}$ \\
$2 \mathrm{nd}$ & $0.025-0.050$ & $2.93 \times 10^{-4}$ \\
$3 \mathrm{rd}$ & $0.105-0.500$ & $2.13 \times 10^{-2}$ \\
$4 \mathrm{th}$ & $0.050-0.105$ & $1.26 \times 10^{-3}$ \\
$5 \mathrm{th}$ & Bentonite & Impermeable \\
\hline
\end{tabular}

Table 2. Simulation parameters

\begin{tabular}{cc}
\hline parameter & value \\
\hline saturated water content: $\theta_{\mathrm{s}}[1$ st layer] & 0.321 \\
residual water content: $\theta_{\mathrm{r}}[1 \mathrm{st}$ layer] & 0.0024 \\
$\alpha$ (for van Genuchten model) $(1 / \mathrm{cm})$ [1 st layer] & 0.266 \\
$n$ (for van Genuchten model) [1 st layer] & 5.989 \\
longitudinal dispersivity: $\alpha_{\mathrm{L}}(\mathrm{cm})$ & \\
1 st layer & $2.2 \times 10^{-2}$ \\
2 nd layer & $1.5 \times 10^{-3}$ \\
3rd layer & $1.3 \times 10^{2}$ \\
4 th layer & $2.6 \times 10^{-3}$ \\
1 st layer & $4.0 \times 10^{-3}$ \\
2 nd layer & $2.7 \times 10^{-4}$ \\
3rd layer & $2.3 \times 10^{-3}$ \\
4 th layer & $4.7 \times 10^{-4}$ \\
transverse dispersivity: $\alpha_{T}(\mathrm{~cm})$ & $1.0 \times 10^{-5}$ \\
molecular diffusion coefficient: $D_{M}(\mathrm{~cm} / \mathrm{s})$ & 0.5 \\
finite difference mesh interval: $\Delta x, \Delta y(\mathrm{~cm})$ & $2.0 \times 10^{-2}$ \\
\hline
\end{tabular}


area is shown in Fig. 1. The 5 th layer (bellow the line CD) is impermeable layer, and the layers from 1 st to 4 th are the area (ABCD) to be simulated. The boundary BC is the hydrostatic pressure boundary of saltwater. The boundary $\mathrm{DE}$ is the hydrostatic pressure boundary of fresh water. The boundaries $\mathrm{AB}, \mathrm{AF}$ and $\mathrm{EF}$ are the no flux boundaries. The parameters used for the simulation are listed in Table 2. The dispersivities $\alpha_{\mathrm{L}}$ and $\alpha_{\mathrm{T}}$ are determined from the mean soil diameters. The unsaturated parameters of the 1 st layer
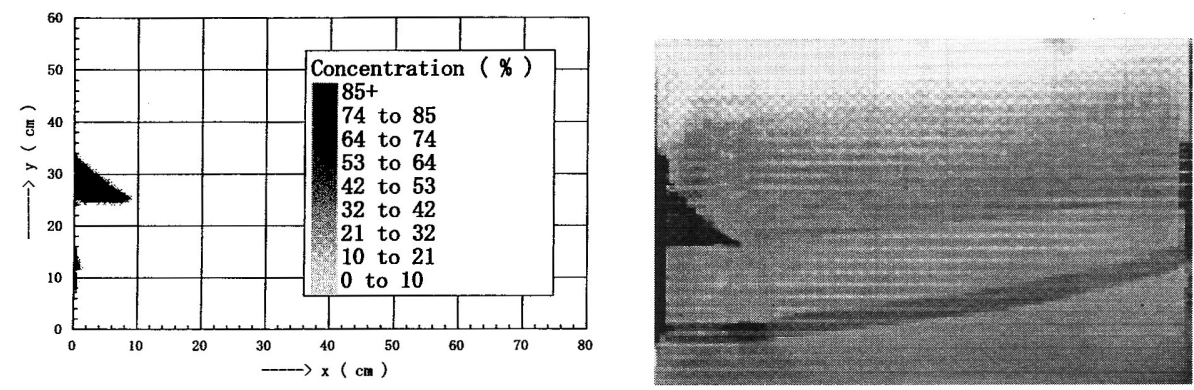

(a) after $30 \mathrm{~min}$.
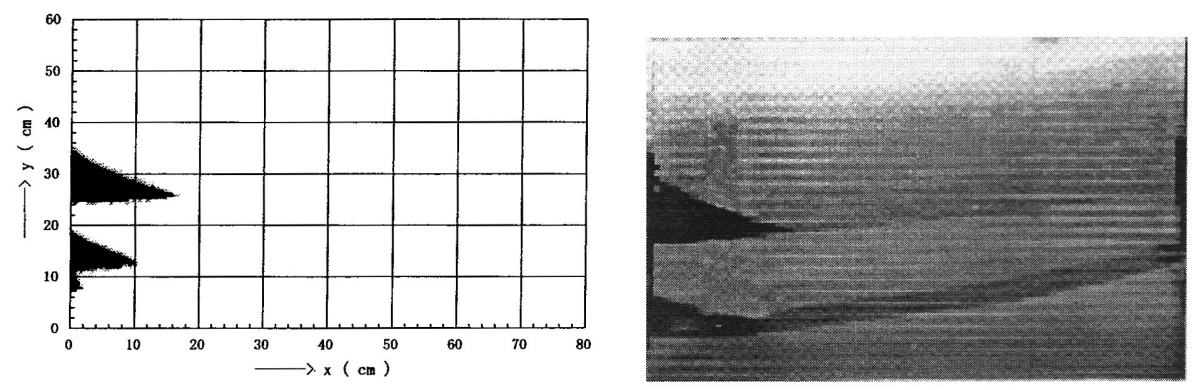

(b) after $720 \mathrm{~min}$.
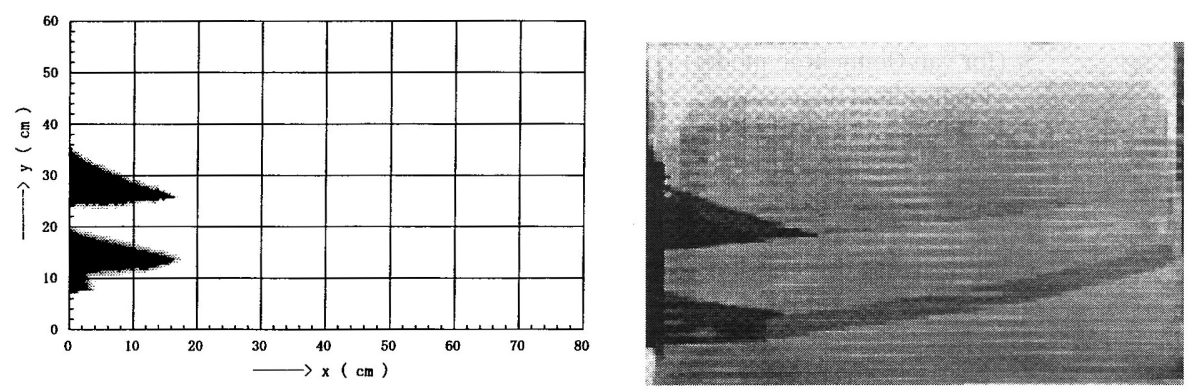

(c) after $2160 \mathrm{~min}$.

Fig. 2. Saltwater intrusion movement 


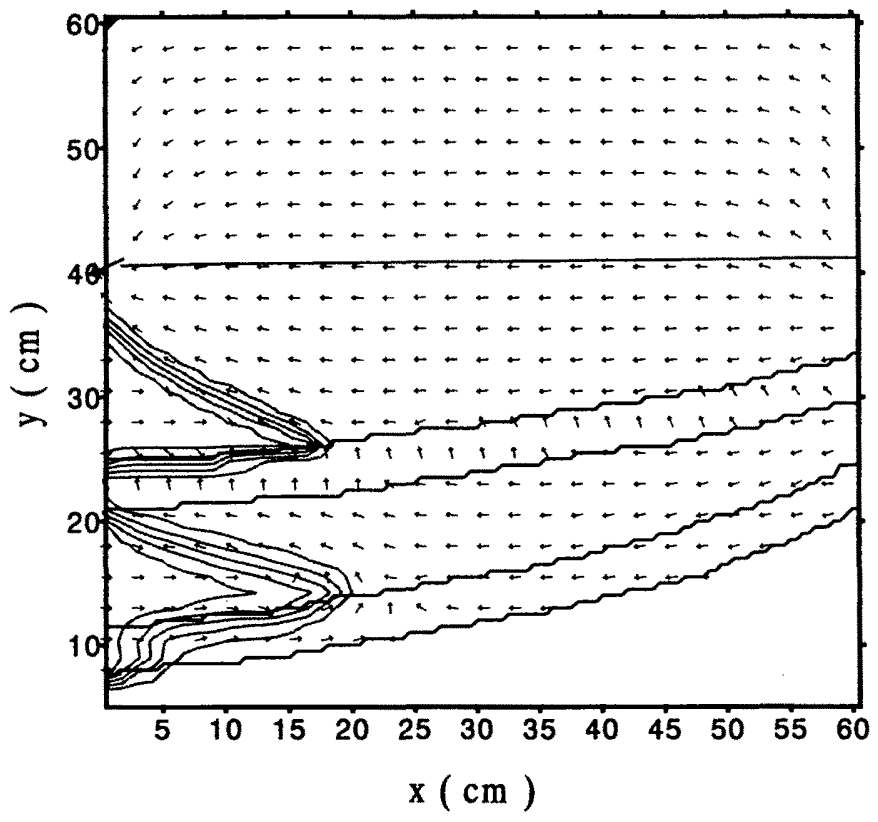

Fig. 3. Velocity vector and contour line plot $(10-90 \%, 20 \%$ interval)

Concentration ( $\%$ )

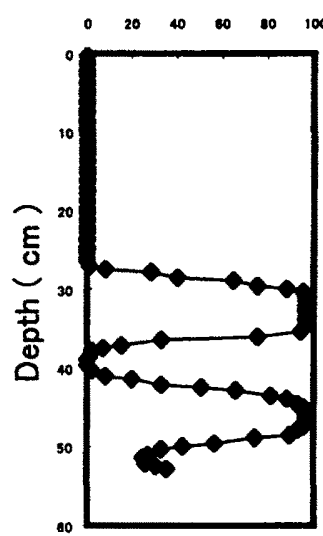

Concentration ( $\%$ )

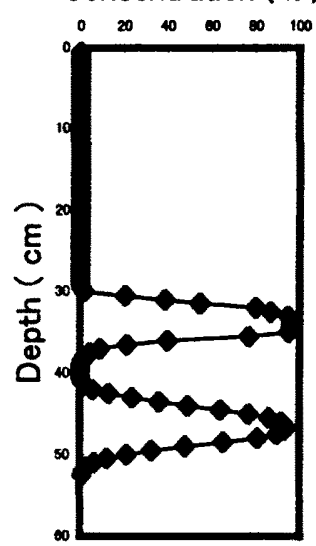

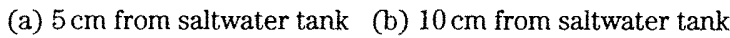

Fig. 4. Vertical profiles of saltwater concentration 
soil are evaluated for the theoretical equations given by van Genutchen (1980). Figure 2 shows the picture of the concentration distribution of experiments and the results of the numerical simulation. The microscopic flow direction by the simulation is depicted in Figure 3. Figure 4 shows vertical profiles of the saltwater concentration at selected points. The results of the present simulation should be useful for the saltwater intrusion in a heterogeneous stratified aquifer.

The characteristics of the saltwater intrusion into each layer are summarized as follows;

1) 1 st layer: In this layer, the groundwater is unconfined. The speed of the saltwater intrusion is faster than that in the other layers. The fresh water flow takes place toward the saltwater tank. At the initial stage, the intrusion of saltwater into this layer is fast but it becomes slow as time passes. The shape of the saltwater approaches equilibrium.

2) 2 nd layer: The saltwater intrusion did not occur during the experiment. This layer can be regarded as an aquiclude.

3) 3 rd layer: In this layer, the groundwater can be confined, since the 4 th layer is also low permeable. The speed of the saltwater intrusion is slower than that in the $1 \mathrm{st}$ layer. The fresh water tends to be pushed toward the upper low permeable layer although its speed is very slow. It seems that the fresh water in the 3 rd layer can hardly occur toward the saltwater tank in this experimental condition.

4) 4 th layer: A slight intrusion of the saltwater is observed in this layer. However, the speed of the intrusion is slow compared to the 3 rd layer.

5) The width of the mixing zone in the 1 st layer is sharp compared to the 3 rd layer. This is due to the fact that the fresh water transports the diluted saltwater along the mixing zone toward the saltwater tank.

\section{CONCLUSION}

Through the laboratory experiment, the fundamental behaviors of the saltwater intrusion in the heterogeneous stratified layers are studied. Specifically the difference of the speed between the unconfined and confined layers is clarified. In order to examine the detailed processes of the saltwater intrusion, the numerical simulation has been made. The detailed velocity profile and the range of the mixing zone are obtained.

\section{REFERENCES}

Bear, J. and Dagan, G. 1964 Moving interface in coastal aquifers. J. Hydr. Div. ASCE, 90(HR4): 193-216

Collins, M. A. and Gelhar, L. W. 1971 Seawater intrusion in layered aquifers. Water Res. Res., 7(4): $971-979$

Henry, H. R. 1959 Salt intrusion into freshwater aquifers. J. Geophys. Res., 64(11): 1911-1919

Huyakorn, P. S. and Pinder, G. F. 1983 Computational method in subsurface flow. Academic Press, New York.

Jinno, K and Ueda, T. 1978 On the numerical solutions of convective dispersion equation by shifting particles. Transactions of JSCE, 10: 126-129

Mualem, Y and Bear, J. 1974 The shape of the interface in steady flow in a stratified aquifer. Water Res. Res., 10(6): 1207-1215 
Pinder, G. F. and Cooper, H. H. 1970 A numerical technique for calculating the transient position of the saltwater front. Water Res. Res., 6(3): 875-880

van Genuchten, M. T. 1980 A closed-form equation for predicting the hydraulic conductivity of unsaturated soils, Soil Sci. Soc. of America J., 44: 893-898 